\title{
TRADICIÓN Y CAMBIO EN LAS POLÍTICAS URBANAS Y LA CONSERVACIÓN DEL PATRIMONIO EN EL BARRIO DE SAN PEDRO DEL CENTRO HISTÓRICO DE CUSCO, DURANTE LA GESTIÓN MUNICIPAL 2011-2014 ${ }^{(*)}$

\author{
TRADITION AND CHANGE IN URBAN POLICIES AND HERITAGE PRESERVATION IN THE SAN PEDRO
} NEIGHBORHOOD OF CUSCO'S HISTORIC CENTER , DURING THE 2011-2014 MUNICIPAL GOVERNMENT
}

\author{
PEDRO FERNÁNDEZ DÍAZ ${ }^{[\star *)}$, KENNY ÁLVAREZ TITO $^{[\star \star \star)}$, VÍCTOR QUISPE CALLO $^{(\star \star \star \star)}$, YONI PACHECO HUACAC $^{(\star \star \star \star \star)}$,

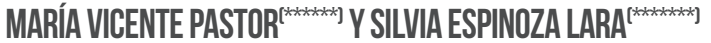 \\ Universidad Nacional San Antonio Abad del Cusco (Perú) \\ pedrojavier@yahoo.es
kennyrobert_at@hotmail.com vmarcelinoquispec@hotmail.com yonipachecoh@gmail.com
maricarmvic@gmail.com espinozalarayaneth@gmail.com \\ Fecha de recepción: 04 de agosto de 2018 \\ Fecha de aprobación: 03 de diciembre de 2018
}

\begin{abstract}
RESUMEN
El presente trabajo se centra en las herramientas más destacables que se han empleado para la protección y gestión del patrimonio cultural en el tradicional barrio de San Pedro, ubicado en el lado suroeste del Centro Histórico del Cusco. Se analizan los diferentes planes de desarrollo urbano aplicados en la ciudad del Cusco; las políticas del Instituto Nacional de Cultura; misiones como la Misión Kubler, que se limitan a impartir recomendaciones para la conservación y protección de los inmuebles prehispánicos y virreinales. Además, se aborda una experiencia de Cooperación Técnica Internacional, que se practicó en la manzana No. 127; los trabajos de la ONG Guamán Poma de Ayala y la World Monument Watch, rehabilitando casonas y viviendas para mejorar el nivel de vida de 302 habitantes. A manera de conclusión, se expone una propuesta que reúne conceptos e interrogantes centrales para determinar la conformación de un ente gestor adecuado, que reúna instituciones públicas y privadas bajo el liderazgo de la municipalidad provincial, de forma que cuenten con respaldo político y financiero para realizar sus labores.
\end{abstract}

\section{PALABRAS CLAVE}

Barrio de San Pedro; Centro Histórico del Cusco; Plan Maestro

\begin{abstract}
The following study focuses on the most remarkable tools employed in the protection and management of cultural heritage in the traditional neighborhood of San Pedro, located in the southwest area of the Historic Center of Cusco. It analyzes different urban development plans for the city of Cusco; the institutional policies of the National Culture Institute (INC, in Spanish); missions such as Kubler's Mission, which are limited to providing recommendations for the conservation and protection of pre-Hispanic and colonial real estate. Also, the study broaches an instance of International Technical Cooperation, which was carried out in Block No. 127, by the NGO Guaman Poma de Ayala and the World Monument Wach. It rehabilitated mansions and houses in order to improve the standard of living of 302 inhabitants. To conclude, we put forth a proposal that combines concepts and central questions to determine the formation of an appropriate management entity. The latter should be composed of public and private institutions under the leadership of the provincial municipality, so that it obtains the necessary political and financial backing to carry out its tasks.
\end{abstract}

\section{KEYWORDS}

San Pedro neighborhood; Historic Center of Cusco; Master Plan

\footnotetext{
(*) El presente artículo fue desarrollado en el marco de la investigación para el curso Taller de Conservación de Centros y Sitios Históricos de la maestría de Arquitectura, con mención en Gestión del Patrimonio Cultural, Centros y Sitios Históricos, de la Facultad de Arquitectura e Ingeniería Civil de la Universidad Nacional San Antonio Abad del Cusco (UNSAAC), dictado por el MSc. Arq. José Hayakawa Casas, en 2018. $\left.{ }^{(* *}\right)$ Arquitecto y maestrando en Arquitectura con mención en Gestión del Patrimonio Cultural, Centros y Sitios Históricos por la UNSAAC. $\left.{ }^{(* * *}\right)$ Arquitecto y maestrando en Arquitectura con mención en Gestión del Patrimonio Cultural, Centros y Sitios Históricos por la UNSAAC. (***) Abogado, antropólogo y maestrando en Arquitectura con mención en Gestión del Patrimonio Cultural, Centros y Sitios Históricos por la UNSAAC.

(*****) Historiadora y maestranda en Arquitectura con mención en Gestión del Patrimonio Cultural, Centros y Sitios Históricos por la UNSAAC.

(******) Arquitecta y maestranda en Arquitectura con mención en Gestión del Patrimonio Cultural, Centros y Sitios Históricos por la UNSAAC. (******) Arqueóloga y maestranda en Arquitectura con mención en Gestión del Patrimonio Cultural, Centros y Sitios Históricos por la UNSAAC.
} 
devenir Vol. 6, N¹1, ENERO - JUNIO 2019, PP. 49-68 - ESTUDIOS I ISSN 2312-7562 I E-ISSN 2616-4949

UNIVERSIDAD NACIONAL DE INGENIERÍ, LIMA.

doi: https://doi.org/10.21754/devenir.v6i11.633
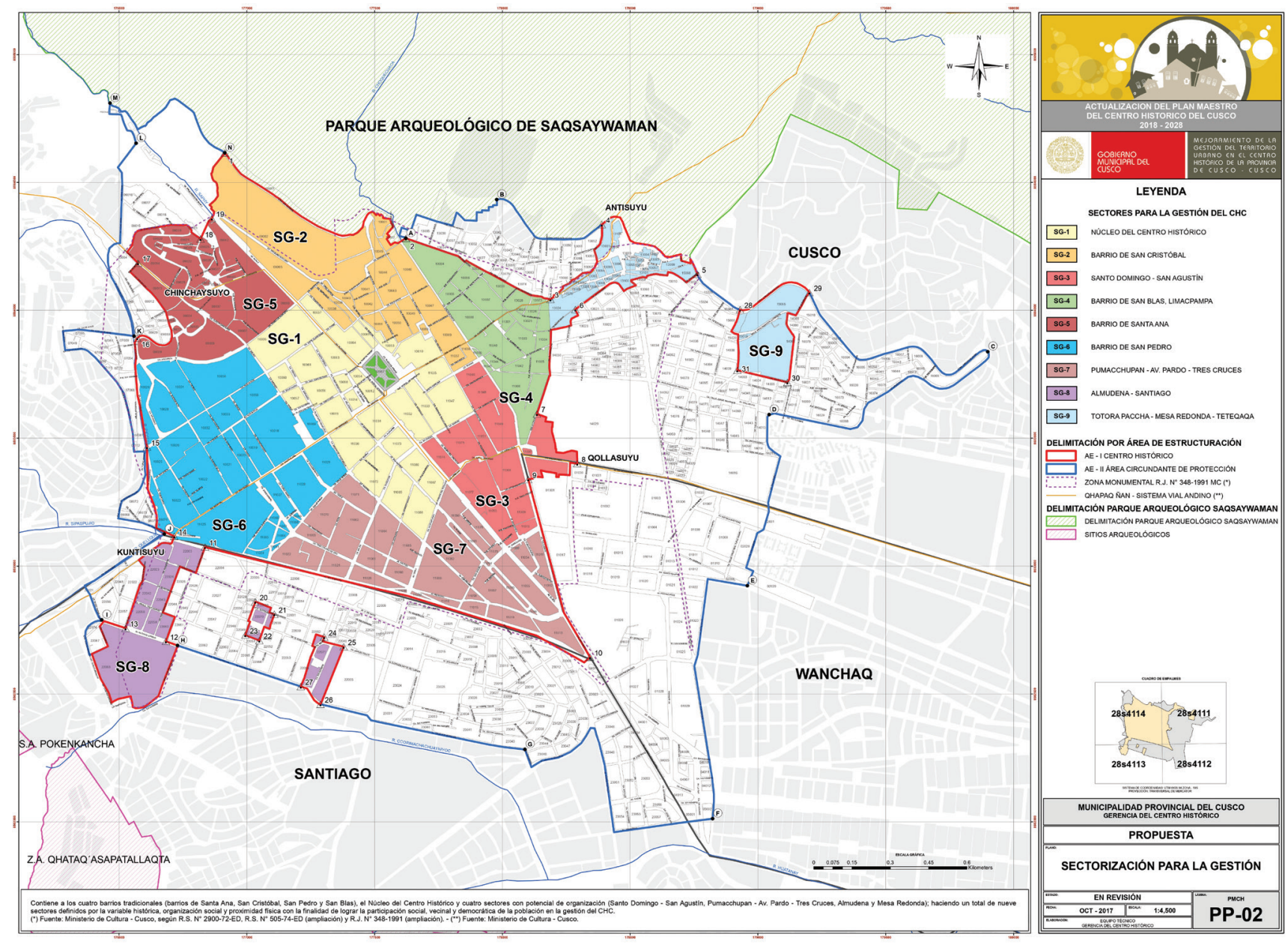

Figura 1. Ubicación del barrio de San Pedro (color celeste), dentro del Centro Histórico del Cusco. Archivo de la Municipalidad Provincial del Cusco - Gerencia del Centro Histórico del Cusco.
El barrio de San Pedro, objeto de este estudio, se encuentra ubicado en la parte suroeste del Centro Histórico del Cusco, enmarcado por las calles Meloc, Arones y Tordo; la plaza San Francisco; las calles Mesón de la Estrella, Cruz Verde, Nueva, Monjaspata; Avenida del Ejército, Sipaspujio y Avenida Arcopata.

\section{Objetivos del estudio}

Los objetivos de la presente investigación son los siguientes: en primer lugar, conocer a través de una breve reseña histórica el barrio de San Pedro en sus diferentes épocas (incaica, colonial, republicana y contemporánea); en segundo lugar, analizar los sucesivos planes urbanos, acontecimientos importantes y políticas públicas para la protección del patrimonio cultural en el Centro Histórico del Cusco, barrio de San Pedro, desde la Ley General sobre el Patrimonio Cultural No. 664 hasta el Plan Maestro del Centro Histórico del Cusco, del año 2005; en tercer lugar, exponer los resultados y logros de los diferentes planes y políticas institucionales en la gestión del Centro Histórico del Cusco - barrio de San Pedro; y, por último, analizar la gestión municipal del economista Luis Flórez García, alcalde del Cusco, durante el periodo 2011-2014. Así mismo, se busca analizar la problemática del barrio de San Pedro e identificar qué institución debe liderar y gestionar dicho espacio, así como también contribuir a esta labor. 
Tradición y cambio en las Politicas urbanas y la Conservación del patrimonio en el Barkio de San Pedro del Centro Histórico de Cusco, DURANTE LA GESTIÓN MUNICIPAL 2011-2014

Pedro Fernández Diaz, Kenny Álvarez Tito, Victor Quispe Callo, Yoni Pacheco Huacac, María Vicente Pastor y Silvia Espinoza Lara doi: https://doi.org/10.21754/devenir.v6i11.633

MUNICIPALIDAD DEL CUSCO

\section{CANAL INKA DE TRANSICION (SIGLO XVI)}

Durante los trabajos de intervención del Plan de Monitoreo Arqueológico de la Calle Nueva Baja, ejecutado el año 2012 por la Municipalidad Provincial del Cusco, se evidencia un segmento de estructura correspondiente a un Canal Inka de transición.

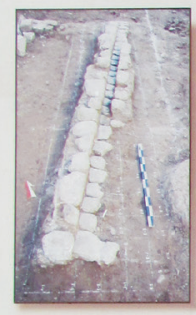

El canal es de manufactura inka de transición, presenta un enlucido de barro con cal esté compuesto por dos hileras de líticos de materio caliza, diorita verde y arenisca, las caras interncs como externas del canal presentan mamposteria celular unidas con mortero de borro, distribuido de manera longitudinal hacia la calle Nueva Baja, el canal tiene la ongitud de $3.99 \mathrm{mt}$. y el ancho e $0.50 \mathrm{mt}$. la solera esta trabajada con canto rodado distribuido linealmente en medio del canal, el ancho de la solera varía de 0.12 a $0.15 \mathrm{mt}$., dicho canal se encuentra asociado a fragmentos de cerámica inka, colonial y osamenta.

El canal fue parte del sistema de irrigación y abastecimiento de agua para las andenerías existentes en época inka e inka

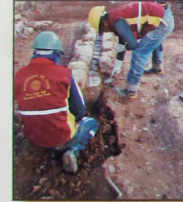
de transición fue una tecnología Anding reutilizada en Ia época de la Colonia.

Las medidas preventivas aplicadas a las estructuras con la finalidad de poner en valor el canal y su conservación in situ, fueron mediante las siguientes técnicas: reticuiado, desarmado $y$ armado de restitución, emboquillado y sellado

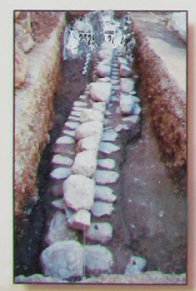
en una caja de concreto diseñada en una caja de concreto diseñada
para su conservación.
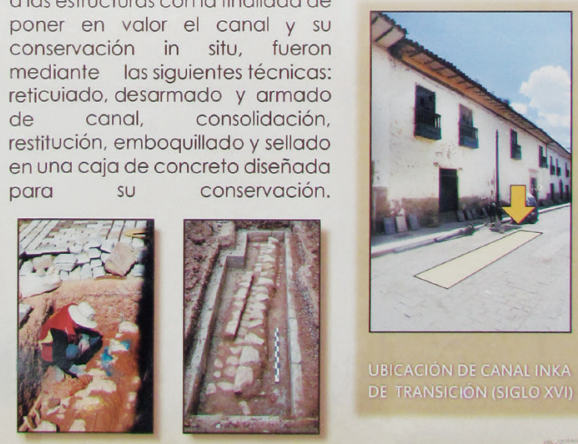

Figura 2. El grabado muestra que el barrio San Pedro era periférico, una zona agrícola (calle Nueva Baja). Archivo personal de los autores.

\section{Breve reseña histórica}

\section{Época incaica}

El actual barrio de San Pedro corresponde a los que en la época inca eran los barrios periféricos de la ciudad, entonces denominada Chaquilchaca. Prueba de ello es el grabado que existe en la calle Nueva Baja (ver Figura 2). En este, se muestran canales inca y restos hallados durante una intervención, según señala el Arq. Santiago Agurto Calvo en su libro La Traza Urbana de la Ciudad Inca.

La ciudad del Cusco se organizaba en función de un sistema vial, cuyos elementos principales estaban constituidos por los caminos que conducían a los Cuatro Suyos. Precisamente, el camino del Contisuyo cruzaba por el barrio de San Pedro: iniciaba en la Plaza de Wakaypata, por el denominado eje procesional, y continuaba por la plaza San Francisco (calles Santa Clara, San Pedro y Hospital, hacia la calle Almudena).

El patrón de asentamiento urbano era un sistema constituido por manzanas o canchas cuadrangulares separadas por vías estrechas. Las canchas, cuyos lados podían llegar a medir tan poco como 30 metros, se adaptaban a la topografía urbana modificando su forma básica. Las vías de circulación eran sensiblemente rectas, con intersecciones prácticamente perpendiculares y anchos de 2.9 a 3 metros, y rara vez superaban los 


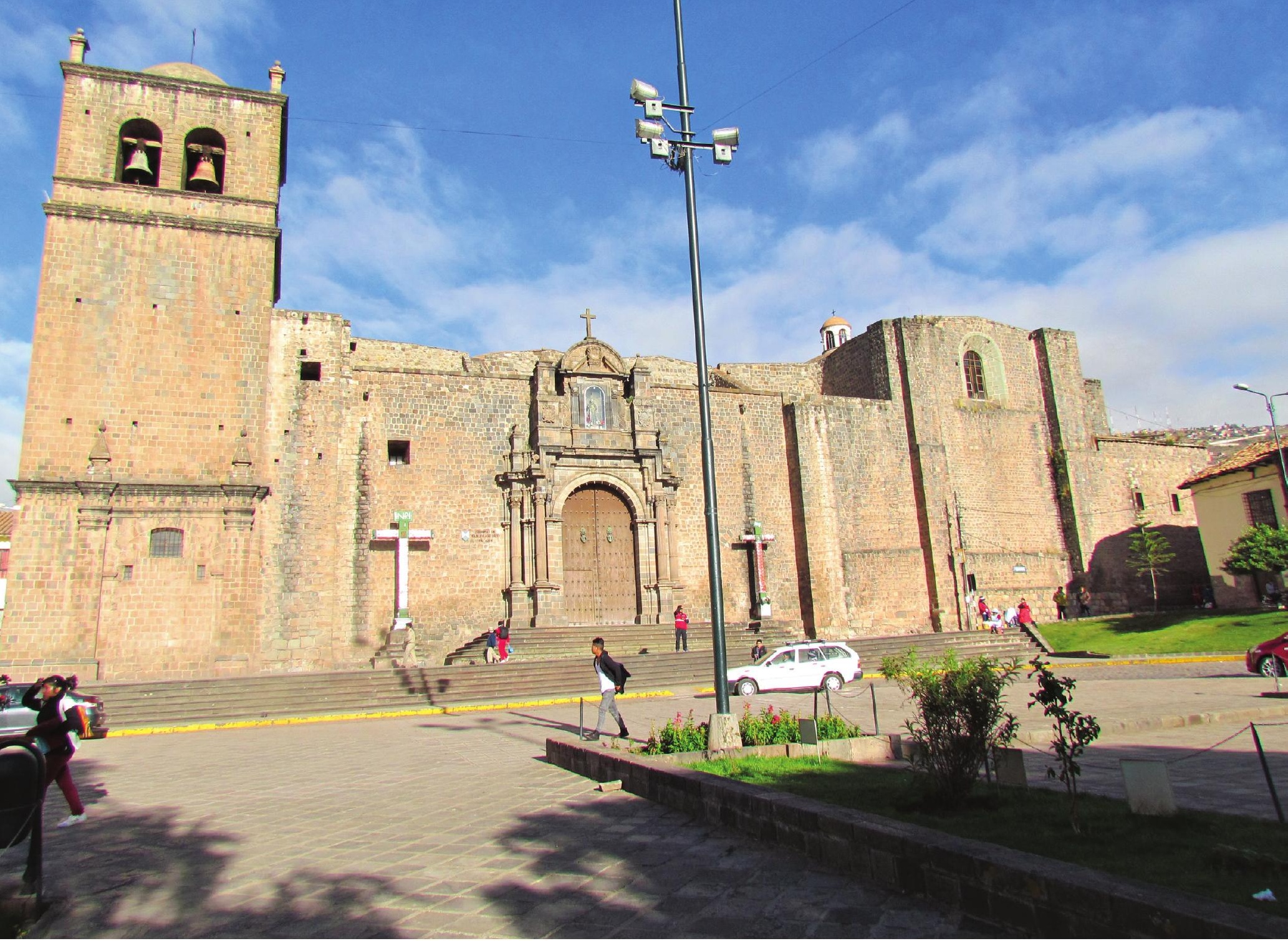

Figura 3. Templo de San Francisco. Archivo personal de los autores.

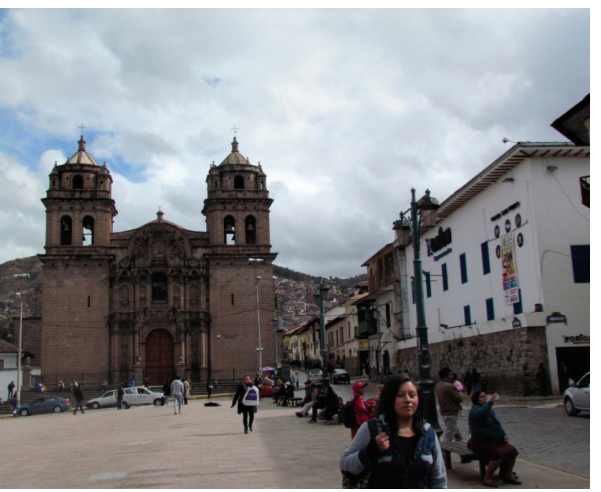

Figura 4. Templo de San Pedro. Archivo personal de los autores.
4.5 metros. Como lo menciona Agurto Calvo (2001), "la ciudad tenía como patrón de agrupamiento arquitectónico un sistema de patios rodeados por construcciones rectangulares de un piso. Dichos edificios eran generalmente unicelulares y en número de cuatro a ocho se conjugaban para conformar un conjunto arquitectónico" (p. 20).

\section{Época colonial}

Los españoles impusieron sus patrones de asentamiento: emplearon el trazado urbano tipo damero. Así, se crearon las calles Vitoque, Desamparados, Chaparro, Unión, Hospital (donde se ubicaba el Hospital de los Naturales), San Pedro, Queshua, Bayoneta, Avenida Alta, Avenida Baja, Nueva Alta, Meloc, Arones, Tordo, Concebidayoc, Cruz Verde; las plazas San Francisco y San Pedro; y otros ambientes urbanos. Las manzanas fueron diseñadas de acuerdo a sus intereses, para facilitar el cobro de tributos y el adoctrinamiento.

Como se ha descrito, durante el dominio inca el barrio de San Pedro era un barrio periférico, con áreas agrícolas, andenes y canales de regadío. Por lo tanto, las calles son de traza urbana colonial, la cual se integra a la ciudad inca; no se destruyó allí ningún palacio inca, como sí ocurrió en la Plaza de Armas, donde se destruyó palacios como el Suntur Wasi o Cora Cora para construir templos católicos.

En esa época, se construyeron en el barrio de San Pedro tres importantes monumentos religiosos: el convento y templo de San Francisco, fundado por Fray Pedro Portugués en 

devenir Vol. 6, N¹1, ENERO - JUNIO 2019, PP. 49-68 - ESTUDIOS I ISSN 2312-7562 I E-ISSN 2616-4949

UnIVERSIDAD NACIONAL DE INGENIERÍA, LIMA

doi: https://doi.org/10.21754/devenir.v6i11.633

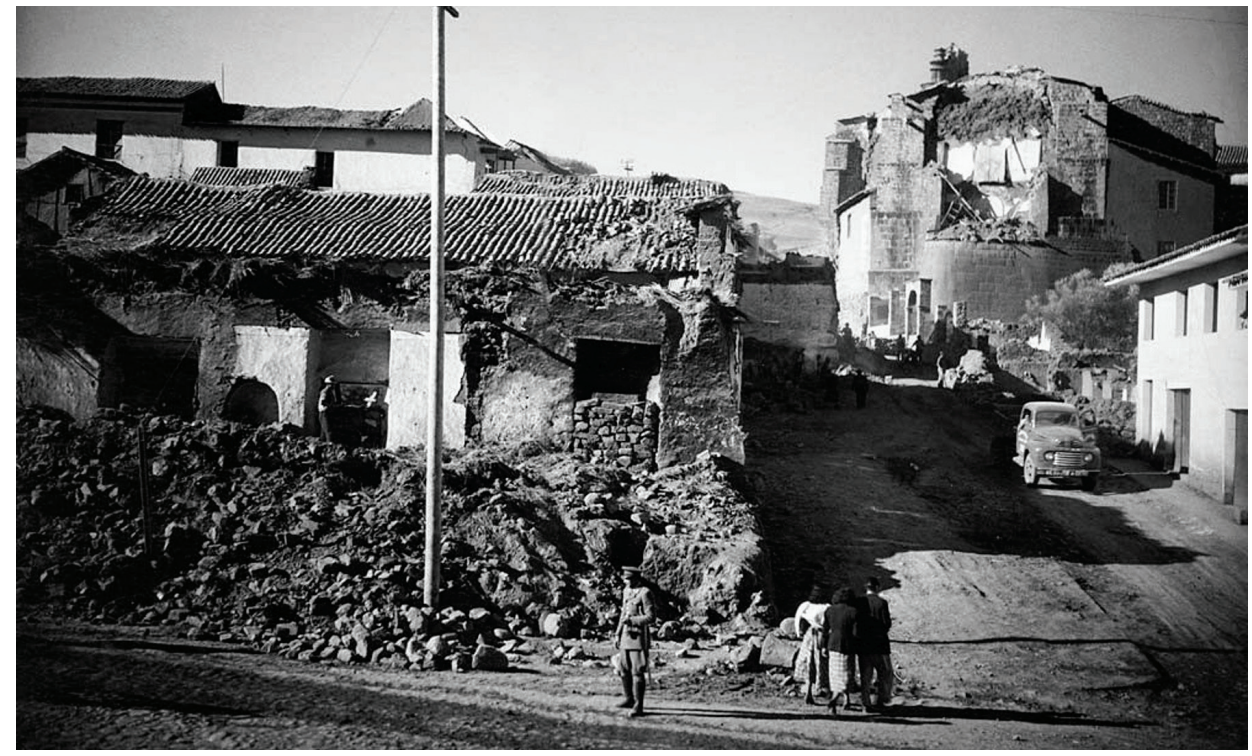

Figura 7. Trabajos de remoción de escombros tras el terremoto de 1950. Archivo de M. Chambi.

que, en primer lugar, sirvió como estación de embarque ferroviario, hasta 1998, para quienes viajaban a Quillabamba y Machu Picchu, luego de la interrupción de la vía a Quillabamba en el kilómetro 122 ocasionada por un huayco. Actualmente, se utiliza como terminal para los recorridos hacia Machu Picchu. Después se crearon los paradores turísticos en Poroy y Ollantaytambo, que significaron la disminución de la cantidad de pasajeros que llegaban al Cusco en tren. Sin embargo, sigue siendo un elemento perturbador en el barrio, pues permanece la línea férrea que cruza la ciudad por su interconexión con la estación ferroviaria de Wánchaq. La línea férrea sube por el cerro Picchu, salvando el desnivel con zigzags, donde se producen accidentes. Lamentablemente, la posibilidad de su erradicación definitiva resulta compleja, pues está concesionada a una empresa denominada Perú Rail a través de un contrato ley.

En el año 1925, se construyó el Mercado Central o Mercado de San Pedro, bajo el mando de Gustave Eiffel, el mismo que construyó la Torre Eiffel. Inicialmente, se había decidido construir en medio de la plaza San Francisco. Luego de elaborar el proyecto, se inició la obra con la construcción de algunas zapatas y columnas, pero se produjo una protesta de la población de entonces, tras la cual se decidió construir en la Plaza San Pedro, elemento que rompe todos los esquemas en ese entonces y hasta la actualidad, porque produce congestión en un ambiente urbano importante como la plaza San Francisco (ver Figuras 5 y 6 ).

\section{Época Contemporánea}

Uno de los acontecimientos más importantes de la época contemporánea fue el terremoto del 21 de mayo de 1950: un sismo de grado 7 en la escala de Mercalli, que provocó grandes daños materiales: tres mil casas destruidas y más de 100 fallecidos. Entre 30 mil y 40 mil personas quedaron sin albergue. Los daños de las construcciones que fueron afectadas ascendieron a un $70 \%$. Las principales causas que contribuyeron a semejante desastre fueron las deficiencias constructivas, la situación de abandono de las viviendas, y los trabajos de demolición y remoción de escombros dirigidos por el Ministerio de Fomento y Obras Públicas (ver Figura 7).

A raíz del terremoto, afloraron dos corrientes reivindicadoras que se afirmaron en adelante: una de corte conservacionista culturalista, y otra desarrollista modernista. Con 


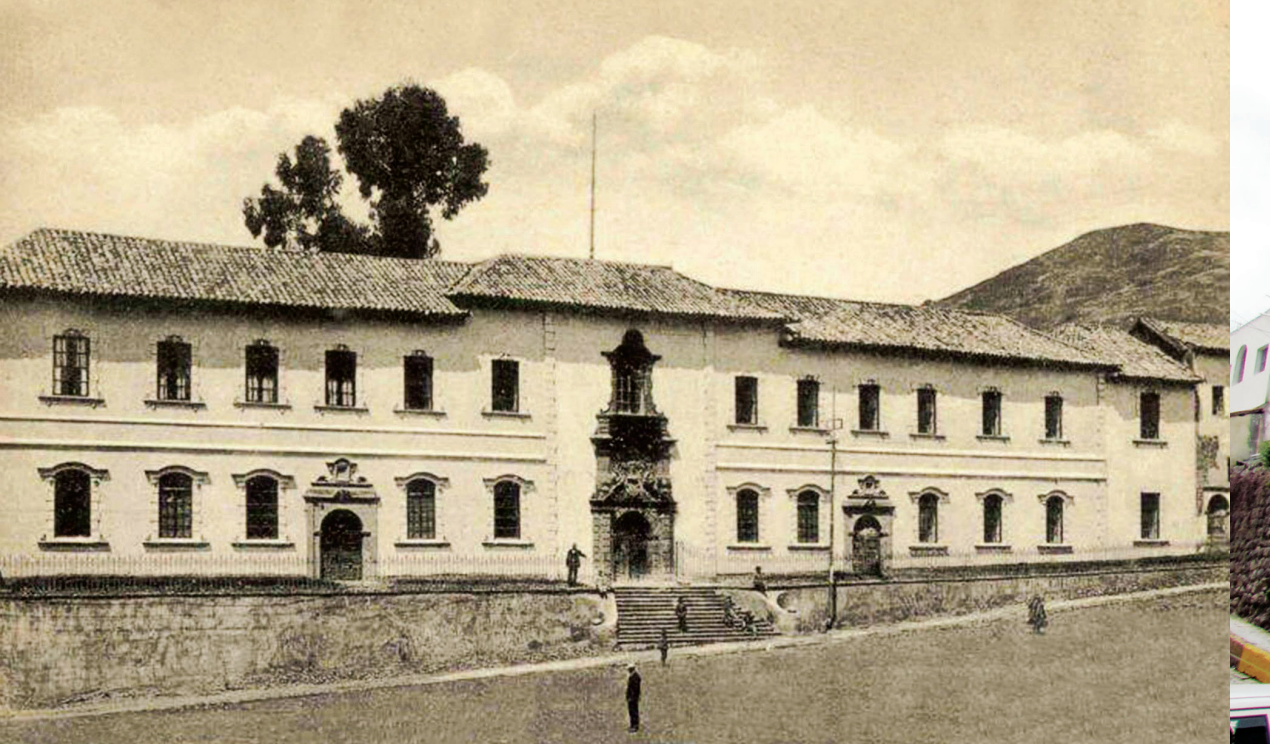

Figura 8. Antiguo Colegio de Ciencias. Archivo de M. Chambi.

el pretexto de desarrollar y supuestamente modernizar el Cusco, los segundos pretenden modificar la traza urbana de la ciudad, partiendo de un falso progresismo que ve lo antiguo como señal de atraso. No parte de una idea clara de cómo se constituye la ciudad, de su necesaria continuidad histórica. Ninguna de estas corrientes evalúa adecuadamente qué debe conservarse y qué no, pues carecen de conocimiento sobre los alcances de la restauración, no trabajan con especialistas y muestran poca preocupación por el legado histórico.

Es durante la época contemporánea que se inicia después del terremoto de 1950, cuando se empieza a tomar conciencia sobre la protección del patrimonio cultural material, debido a la labor de profesionales como el Arq. Oscar Ladrón de Guevara Avilés. Particularmente en el barrio de San Pedro, se construyeron entonces edificaciones contemporáneas, como el local del Colegio Nacional de Ciencias (ver Figuras 8 y 9), sobre un andén inca; y el ex cine Garcilaso, igualmente sobre un andén inca (ver Figura 10), como una expresión de que el Centro Histórico del Cusco es un espacio vivo y no un museo.

Luego del terremoto de 1950, se construyó el cine Ollanta en la calle Meloc, que cuenta con pinturas de alto relieve en su interior. Otro ejemplo de expresión contemporánea es la restitución volumétrica efectuada en el convento de San Francisco, adyacente al templo hacia la plaza San Francisco, aproximadamente en el año 2000 (ver Figura 11).

\section{Sucesión de Planes urbanos y políticas públicas para la protección del pa- trimonio cultural en el Centro histórico del Cusco - Barrio de San Pedro.}

Durante la Colonia y el Virreinato, no se realizó ninguna acción para proteger los monumentos prehispánicos que la ciudad inca del Cusco alberga. El barrio de San Pedro era periférico, una zona agrícola, donde los españoles ampliaron la ciudad sobre canales incas y andenes agrícolas de los que queda testimonio en las calles Santa Clara y Nueva Baja. En el centro del Cusco, sin embargo, los españoles se dedicaron a destruir toda expresión cultural, material o inmaterial. Con el pretexto de la llamada extirpación de idolatrías, se destruyeron los templos incaicos. Las huacas, que eran adoratorios a la Pachamama, el Sol y la Luna fueron reemplazados con cruces de madera o templos cristianos. Recién en la etapa republicana se plantearon algunas normas para prote-
Figura 9. Actual Colegio de Ciencias, edificado sobre andén inca, en la calle Santa Clara. Archivo personal de los autores.. 


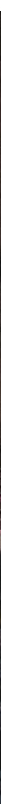

Figura 10. Ex cine Garcilaso, construido sobre andén inca. Archivo personal de los autores.

Figura 11. Restitución volumétrica de una crujía en el Convento San Francisco. Archivo personal de los autores.

ger este patrimonio. En junio de 1929, se promulgó la Ley General sobre Patrimonio Cultural, $N^{\circ} 6634$. En esta, se precisa la propiedad del Estado sobre todos los objetos y monumentos arqueológicos; su condición se determina como inalienable e imprescriptible. Se definió como obligación del Estado la protección del patrimonio cultural. Además, se tomaron medidas concretas para la restauración de diversos templos coloniales. Se crearon los museos Bolivariano y de Arqueología Peruana (Belaunde, 1990).

En 1930, se efectuó el Código de Edificaciones de la ciudad, Ley № 8853 , monumentos coloniales y republicanos. Así mismo, se promulgó la Ley de Expropiaciones, № 9125, que contempla la naturaleza reembolsable de los gastos, el derecho de mejoras que grava a los propietarios beneficiarios. Con la creación del Patronato Nacional de Arqueología, entre 1939 y 1972, funcionó el Consejo de Conservación de Monumentos Históricos (Halanocca, 2011).

Lamentablemente, estas normas han contribuido poco o nada con la gestión del centro histórico, según lo afirma el Arq. Halanocca en su tesis de maestría La Relación Tradición-Modernidad y su incidencia en la protección y conservación del Centro histórico de la ciudad del Cusco, Retrospectiva.

El arquitecto Paulo de Azevedo aclara que la legislación en materia de protección del patrimonio en el Perú puede dividirse en tres etapas. La primera transcurre entre los años 1929 y 1939, etapa en que se crea el Patronato Nacional de Arqueología, por Ley $N^{\circ} 6634$, que indica que el Estado es propietario y está obligado a hacerse cargo de la conservación de los restos prehispánicos. Durante la segunda etapa, entre 1939 y 1972, se creó el Consejo Nacional de Conservación de Monumentos Históricos, por Ley $\mathrm{N}^{\circ}$ 8853. En esta etapa, se reconoce el carácter monumental de los restos arqueológicos y virreinales. En la tercera etapa, se publica el D. S. No 19, en 1961, un reglamento de conservación y restauración de monumentos. Azevedo atribuye el descuido del patrimonio a problemas de organización, administración, presupuestos, competencias y múltiples autoridades.

El primer antecedente moderno para revalorar el patrimonio existente en la ciudad se realizó con la Comisión Técnica para la Restauración de Monumentos del IV Centenario de 
la Fundación Española del Cusco, presidida por el prefecto coronel Jorge Vargas, tesorero; el obispo Dr. Pedro Pascual Farfán; y el asesor entre 1933 y 1934, el Arq. Emilio Harth-Terré.

En la primera mitad del siglo XX se ejecutó la canalización del río Saphi, entre Plateros, Portal del Comercio y Confituría; la restauración de la compañía de Jesús; y la apertura del Museo Arqueológico de la calle Tigre, según afirma Roberto Garmendia.

La conservación del patrimonio cultural, particularmente del Centro Histórico del Cusco, en realidad se inicia en la primera mitad del siglo XX, con normas y leyes que rigen a nivel nacional. Ello ocurrió luego del terremoto de 1950, oportunidad en la que se destruyó aún más el patrimonio con el pretexto de modernizar la ciudad. Fue entonces que surgieron opiniones que opusieron dicha pretensión de modernización, como la del Arq. Oscar Ladrón de Guevara. De esta manera, se comenzó a tomar conciencia de la importancia del patrimonio y se crearon organismos como la Corporación de Reconstrucción y Fomento del Cusco (CRIF), y se elaboró y aplicó lo estipulado por la Misión Kubler.

\section{La Misión Kubler de 1951}

A falta de acuerdo para la restauración, la conservación de los monumentos y la reconstrucción de la ciudad, se solicitó el apoyo a la Unesco. La misión técnica, la primera en su género, llega en 1951. Estuvo conformada por el profesor George Kubler, de la Universidad de Yale; el Arq. Luis Mac Gregor Ceballos, de México; y el Arq. Oscar Ladrón de Guevara, de Cusco.

Las recomendaciones de la Misión Kubler de 1951 son superadas por la emergencia del momento. Representa el inicio de la protección y conservación del patrimonio cultural local, bajo la influencia de teorías y conceptos ambiguos, dominada por la restauración ortodoxa de monumentos singulares, la conservación de espacios urbanos y la modernización de la ciudad. Con una visión monumental físico-espacial, sin reconocerlo como Centro Histórico, en base a sus recomendaciones, se delimita la ciudad e identifican tres sectores con tratamiento diferenciado: la incaica, la virreinal y la moderna, sin reconocer el periodo republicano (Kubler, 1951).

La Misión Kubler entiende la conservación como el mantenimiento de la forma original de un monumento con escaso uso de medios modernos. Esta restauración consiste en reemplazar los elementos destruidos con asistencia de la técnica moderna. Para este caso, no se tenía mano de obra calificada (Kubler, 1951) y no se tomó en cuenta la pervivencia de prácticas constructivas ancestrales.

La Misión Kubler definió la línea de intervención. En primer lugar, es monumental, porque plantea que se debe conservar aquellos edificios con reconocido valor artístico e histórico, por ejemplo, la Casa Garcilaso y el Palacio Arzobispal. Así mismo, es cultural, puesto que permite el cambio de uso residencial por el cultural, como en el caso de los dos inmuebles previamente mencionados y la Casa del Almirante, que se convirtieron en museos. Además, es espacial, pues identifica un sector urbano con valores arquitectónicos, urbanos e históricos por proteger. En adelante, también el centro histórico será denominado área monumental. Con esta visión, se orienta su congelamiento.

\section{La Corporación de Reconstrucción y Fomento}

El gobierno creó una serie de instituciones e implementa fondos o incentivos para la reconstrucción y restauración de los monumentos históricos, así como el desarrollo económico de la región. En 1957, mediante la Ley № 12800, surgió la Corporación de Reconstrucción y Fomento (CRIF), primera entidad departamental descentralizada, la cual representaba una tendencia culturalista, con visión económica estatal. Se buscaba, con ello, la conservación de los monumentos arqueológicos y virreinales. 
devenir Vol. 6, N¹1, ENERO - JUNIO 2019, PP. 49-68 - ESTUDIOS I ISSN 2312-7562 | E-ISSN 2616-4949

UNIVERSIDAD NACIONAL DE INGENIERÍA, LIMA

doi: https://doi.org/10.21754/devenir.v6i11.633

La modernización no se entiende como "una respuesta dinámica y permanente a la mejor solución de los problemas de vida del hombre y la sociedad en estrecha interdependencia con su medio físico y cultural" (Sánchez, 1994). Se sugiere respeto al ambiente, y tener la capacidad de proponer una tecnología apropiada, que permita un encuentro satisfactorio entre las respuestas científicas, tecnológicas y modernas, y las prácticas culturales tradicionales.

\section{El Plan Copesco y el desarrollo turístico}

Con los estudios realizados para la preservación y conservación del patrimonio cultural y la articulación con la promoción del turismo cultural en el eje Cusco-Puno-Desaguadero, por la Unesco en 1966, se creó el Plan Copesco con la finalidad de mejorar la infraestructura turística en el eje MachuPicchu-Cusco-Puno-Desaguadero; luego, se convertiría en un proyecto regional.

\section{El proyecto PER-39}

Al interior de la organización de Copesco, se creó en 1973 el Proyecto Especial de Reconstrucción (PER-71-539), más conocido como PER-39, unidad que laboraba en coordinación con el INC de Cusco, con financiamiento de fondos no reembolsables provenientes de la Unesco. No solo llevaron a cabo la rehabilitación de monumentos, sino que también intervinieron en importantes restos arqueológicos localizados en la región. Además, en la ciudad, restauraron Santo Domingo, el Palacio del Almirante, San Bernardo, Almudena, el Seminario de San Antonio Abad y el paraninfo universitario de la Universidad Nacional San Antonio Abad del Cusco.

\section{El Instituto Nacional de Cultura}

Mediante el decreto ley № 1879 de 1971, se creó el Instituto Nacional de Cultura (INC), como organismo público descentralizado del sector educación. Se dispuso la desactivación de la Casa de la Cultura del Perú y el INC asume sus funciones. Este organismo se plantea proponer y ejecutar la política cultural del Estado, proteger y conservar el Patrimonio Cultural de la Nación, difundir la cultura en todos los contextos sociales y favorecer la creatividad de la población (Halanocca, 2011). De este modo, se mejoró sustancialmente la conservación del patrimonio.

\section{El plan de desarrollo urbano de 1970-1973}

El plan, a pesar de haber sido criticado por su origen centralista y vertical, pues fue propuesto por el Ministerio de Vivienda, mantiene la regulación física y espacial de la ciudad, propuesta vial lineal. Propuso, además, por primera vez, la construcción de la Vía de Evitamiento, la Vía Expresa, la reubicación del Mercado Central de San Pedro, y la reubicación de la estación ferroviaria de San Pedro hacia Poroy. Todas estas acciones tenían el fin de descongestionar el Centro Histórico del Cusco; sin embargo, hasta hoy, ninguna se ha llevado a cabo (ver Figura 12).

\section{El sismo de 1986}

El 5 de abril de 1986, Cusco sufrió el embate de un nuevo sismo de regular intensidad, que provocó daños de mediana envergadura. En este contexto, se puso en evidencia las deficiencias y limitaciones de intervenciones pasadas, además de incrementarse los daños en aquellos inmuebles y monumentos que no fueron atendidos o fueron mal refaccionados después del terremoto de 1950. Es decir, las intervenciones realizadas en las décadas precedentes como rigurosas restauraciones no fueron tales, pues luego afloraron problemas técnicos y conceptuales de restauración (Ferreyra \& Ladrón de Guevara, 1989). Las modificaciones y agregados empíricos, la falta de adecuado reforzamiento estructural, la ausencia de mantenimiento, y la reparación de desagües y techos reflejan un 


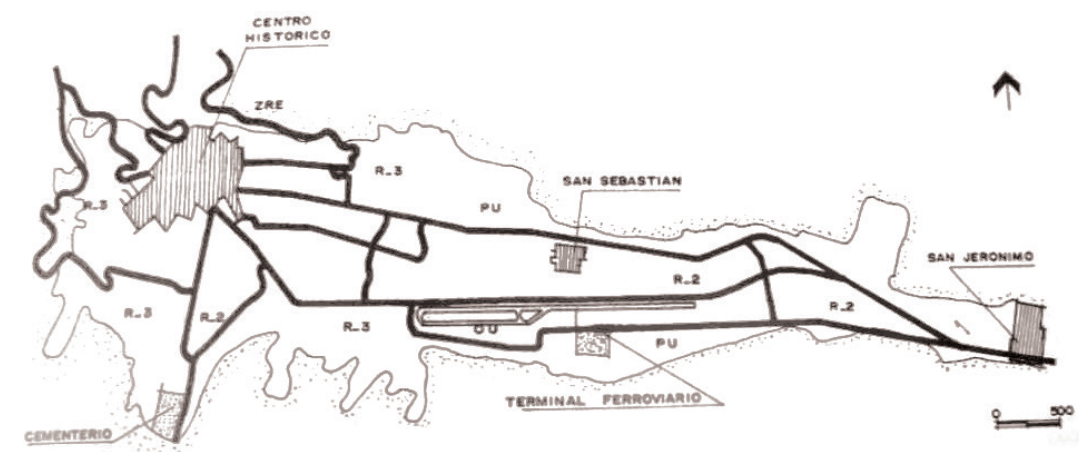

Figura 12. Esquema de expansión urbana, 1973. En Centro Histórico del Cusco Rehabilitación Urbana y Vivienda, por E. Villegas, 1990.

resultado de $50.26 \%$ de edificaciones en mal estado, un $22.60 \%$ en regular estado y un $19 \%$ en buen estado (Villegas, 1990).

La actividad de la conservación entra a una segunda etapa de desarrollo que Hayakawa (1995) ubica entre 1964 y 1990. Dicho autor reconoce que durante esta existe una mayor conciencia histórica, es decir, mejor base ideológica. La preocupación por proteger y conservar el patrimonio cultural alcanza a todo el país, principalmente, a aquellas ciudades poseedoras de gran cantidad de patrimonio. De este modo, Cusco, Arequipa y Trujillo alternan el protagonismo con Lima.

\section{Código Municipal para la protección de la ciudad histórica del Qosqo}

Constituye el primer instrumento de gestión para la protección y revitalización del Centro Histórico del Cusco, elaborado por el Arq. Víctor Pimentel Gurmendi, maestro de la Arquitectura, reconocido por su defensa del patrimonio. Dicho instrumento fue promulgado por la Ordenanza Municipal N 02-A/MQ-SG-92, en junio de 1992, por el alcalde Daniel Estrada Pérez, con el objetivo de:

...promover la protección de la ciudad Histórica del Qosqo, generando una relación armónica entre el centro Histórico, su medio natural y las otras áreas de la ciudad. Así mismo, para mantener la síntesis de los aportes culturales de cada época de su historia; evitar su deterioro y propiciar la revitalización de las estructuras físicas de valor cultural, rescatando usos existentes adecuados, para generar el desarrollo de la ciudad. Es un instrumento de vital importancia para la salvaguarda del patrimonio que conserva dicha ciudad y cuyo valor universal es reconocido y destacado en todo el mundo. (Municipalidad del Cusco, 1993)

\section{Plan Maestro del Centro Histórico del Cusco}

Este plan es un instrumento de gestión importante, elaborado por un equipo técnico constituido por profesionales de la Municipalidad del Cusco y el INC en 2005. Dicho documento establece parámetros urbanísticos para el manejo del centro histórico, cuya vigencia rige hasta hoy.

El Plan Maestro como proceso de gestión planificada, en primer lugar, se orienta a interpretar una realidad compleja actual y preexistente, llena de problemas y contradicciones, para poner fin a un proceso permanente de deterioro, destrucción y transformación inapropiada de su patrimonio material, y a la pérdida de su tejido social y cultura inmaterial. El plan orienta sus propuestas y acciones hacia una efectiva protección y revitalización del centro histórico en su conjunto, así como de sus elementos urbanísticos y arquitectónicos, y actividades sociales, económicas y culturales. En este sentido, el Plan Maestro define un plan de acción expresado en un conjunto de 
devenir Vol. 6, N¹1, ENERO - JUNIO 2019, PP. 49-68 - ESTUDIOS I ISSN 2312-7562 I E-ISSN 2616-4949

UNIVERSIDAD NACIONAL DE INGENIERÍ, LIMA

doi: https://doi.org/10.21754/devenir.v6i11.633
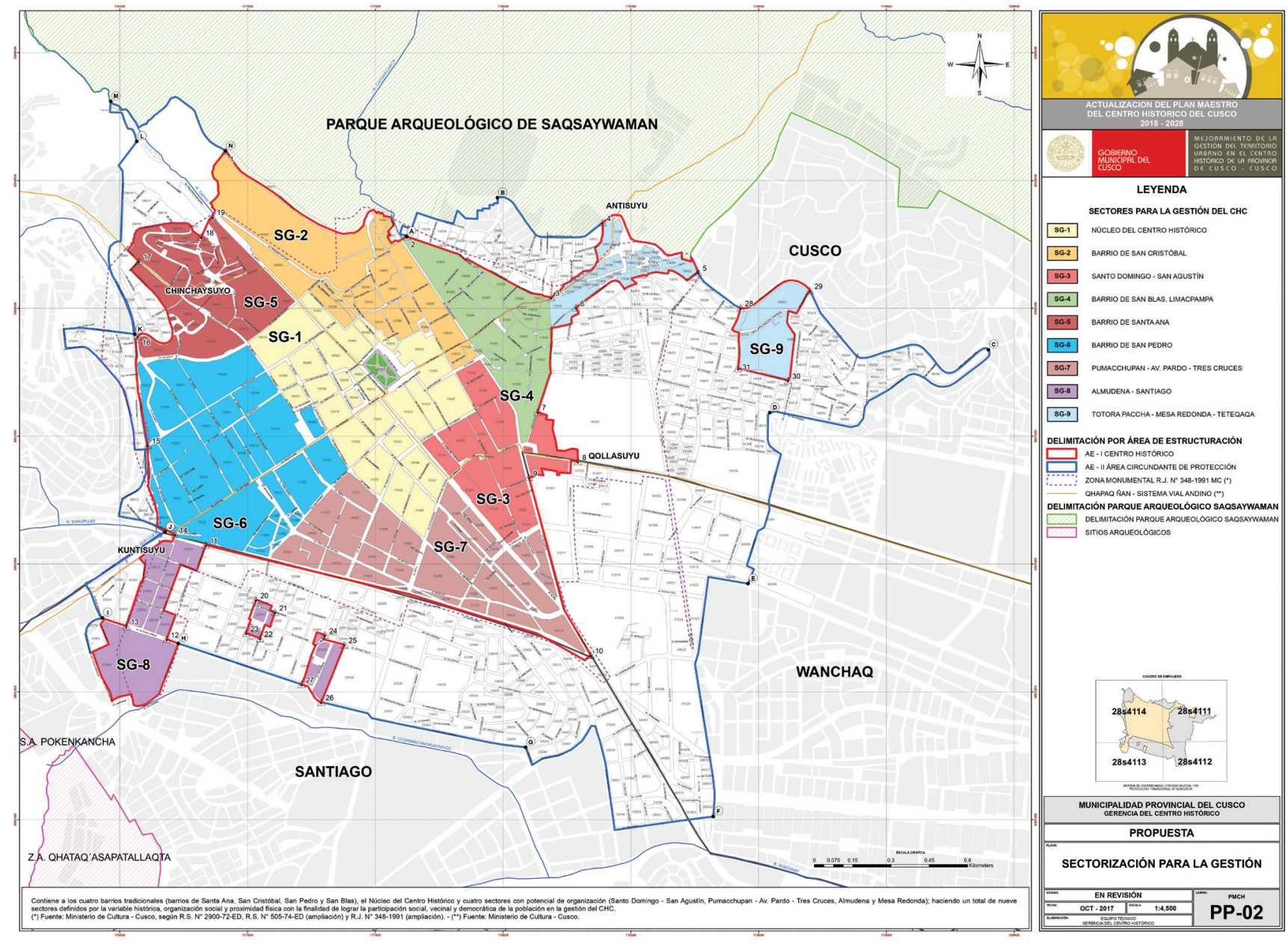

Figura 13. Plano del Centro Histórico del Cusco, barrio de San Pedro. Archivo de la Municipalidad Provincial del Cusco - Gerencia del Centro Histórico del Cusco. programas, proyectos y actividades, así como propuestas normativas que permitirán desarrollar acciones de conservación y puesta en valor del patrimonio heredado, así como mejorar la calidad de vida de sus habitantes.

El barrio de San Pedro, al igual que otros barrios, recién en el presente Plan Maestro está contextualizado y zonificado en el lado suroeste del Centro Histórico del Cusco, delimitado por las calles Arcopata, Meloc, Arones, Tordo, Plaza San Francisco, Mesón de la Estrella, Cruz Verde, Nueva y Avenida del Ejército (ver Figura 13).

El barrio de San Pedro es objeto del presente estudio por mostrar una serie de valores, como el Valor de Uso, Valor Formal y Valor Simbólico que a su vez poseen subvalores (ver Tabla 1).

\section{Cooperación técnica internacional}

Respecto de la Cooperación Técnica Internacional para el barrio de San Pedro, es importante destacar que fue un proceso de cooperación propiciado por la ONG Guamán Poma de Ayala y el Programa World Monuments Watch de la Fundación World Monuments Fund, que posibilitó la rehabilitación de la manzana $N^{\circ} 127$ (barrio de San Pedro, sector I), enmarcada por las calles Unión, Nueva Baja, Chaparro y Plaza San Pedro (ver Figura 14), experiencia que se debe replicar en el Centro Histórico del Cusco en general. La ONG 
Tradición y cambio en las Politicas urbanas y la Conservación del patrimonio en el Bario de San Pedro del Centro Histórico de Cusco, DURANTE LA GESTIÓN MUNICIPAL 2011-2014

Pedro Fernández Díaz, Kenny Álvarez Tito, Víctor Quispe Callo, Yoni Pacheco Huacac, María Vicente Pastor y Silvia Espinoza Lara

doi: https://doi.org/10.21754/devenir.v6i11.633

Tabla 1. Subclasificación de valores patrimoniales para el barrio de San Pedro

\section{VALOR DE USO}

VALOR

PATRIMONIAL

De uso económico

Funcional

Educativo

Social

Científico

\section{DESCRIPCIÓN}

La dinámica económica generada por el Mercado Central y la plaza de San Pedro es determinante, por ser el sustento de cientos de familias.

La funcionalidad de la plaza de San Pedro puede mejorar en relación con remodelar el mercado San Pedro y erradicar la estación ferroviaria.

Este subvalor es importante en la medida que el poblador en general tome conciencia del valor patrimonial de los monumentos que existen en el barrio, como los templos, plazas, casonas y balcones.

Los espacios públicos del barrio pueden mejorar la interacción social del poblador, como la Plaza San Francisco, la Plaza San Pedro y la calle Túpac Amaru.

La investigación arqueológica que se pueda realizar en el barrio, ambientes

urbanos, templos, Hospital de los Naturales, hoy convento de San Pedro, convento de Santa Clara, pueden contribuir al conocimiento de la ciudadanía en general.

\section{VALOR FORMAL}

Técnico o artístico

De originalidad

De conjunto
En el barrio de San Pedro, se encuentran monumentos religiosos con valor artístico monumental y arquitectónico, como los templos y conventos de Santa Clara y de San Pedro, emplazamiento donde en tiempos de la colonia se encontraba el Hospital de los Naturales. El Mercado Central ha adquirido valor patrimonial por ser una expresión de arquitectura de una época, igual que las casonas coloniales.

Existe originalidad de bienes inmuebles, balcones, muros incas como el de la Avenida Santa Clara, conventos y templos, por los estilos y tipología arquitectónica de las casonas, templos de la época colonial y republicana.

Existe un valor de conjunto y armonía que puede mejorar con la erradicación de la estación ferroviaria y el levantamiento de la línea férrea.

\section{VALOR SIMBÓLICO}

Histórico

De existencia

De legado

De identidad

De imagen
El barrio de San Pedro posee un valor histórico intrínseco, por ser testigo de una serie de acontecimientos históricos, los que pueden mejorar con un análisis e investigación de sus principales monumentos como es el ex Hospital de los Naturales, conventos y ambientes urbanos, como la calle Vitoque.

Su existencia en el tiempo contribuye al goce y disfrute de sus habitantes, que interactúan en sus espacios públicos, inmuebles que en su mayoría se conservan como vivienda.

Las generaciones futuras recibirán el legado de la conservación de los bienes culturales del barrio en la medida que se conserve lo importante, y exista un aporte de lo contemporáneo con calidad y respeto a lo existente.

En esta época en que se ha perdido en forma considerable la identidad cultural de una ciudad y barrio importante, es necesario promover e incentivar esta identidad con nuestra cultura y que nos podamos expresar, especialmente en lo arquitectónico, con identidad, inclusive fuera del Centro Histórico del Cusco, conservando nuestras tradiciones y sentimientos espirituales y religiosos.

Es posible conocer a través de los bienes culturales del barrio de San Pedro las razones que dieron origen a nuestra evolución histórica, los cambios producidos y la configuración de una imagen existente en este barrio que aún conserva un "sabor al pasado". 
devenir Vol. 6, N¹1, ENERO - JUNIO 2019, PP. 49-68 - ESTUDIOS I ISSN 2312-7562 I E-ISSN 2616-4949

UNIVERSIDAD NACIONAL DE INGENIERÍA, LIMA

doi: https://doi.org/10.21754/devenir.v6i11.633

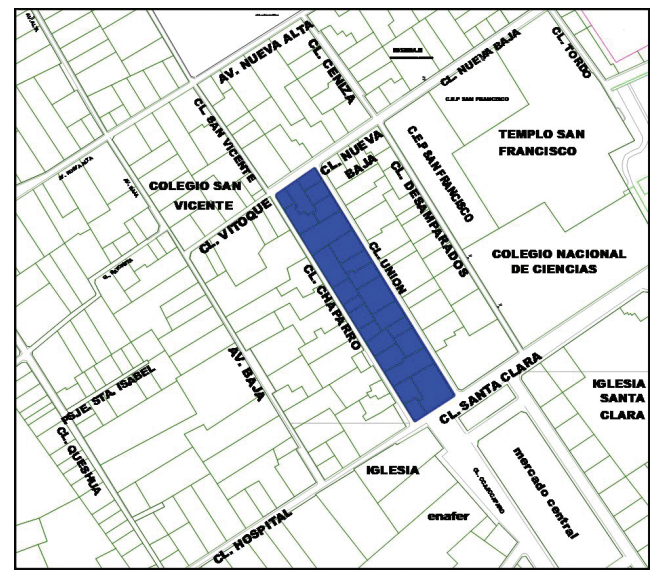

Figura 14. Manzana 127, reforma arquitectónica con saneamiento físico legal, realizada por la ONG Guamán Poma de Ayala y la World Monuments Watch, calles Unión, Chaparro, Nueva Baja y Santa Clara. Elaboración propia.

Guamán Poma, en su publicación Vivienda Social Productiva y Saneamiento en Tugurios del Centro Histórico de Cusco en Perú, manifiesta que benefició a 302 habitantes.

Esta acción no se puede calificar como renovación urbana ni rehabilitación urbana. Se ha tratado de una reforma arquitectónica realizada sin alterar la volumetría de las casonas, con saneamiento físico legal de predios como aclaran la Arq. Diana Ramos y el Arq. José Carlos Hayakawa. En esta reforma, lo positivo ha sido que ha mejorado la calidad de vida de sus habitantes, y se han conservado las características históricas y arquitectónicas del patrimonio por medio de una gestión participativa.

\section{Resultados y Logros de los Planes Urbanos y Políticas Institucionales en la Ges- tión del Centro Histórico - Barrio de San Pedro}

Luego de analizar los sucesivos planes propuestos para la ciudad del Cusco, puede afimarse que aparte de ser genéricos, no han producido efectos positivos en la gestión del centro histórico, ya sea porque en el Perú en general no existe cultura de planificación o porque fueron impuestos verticalmente desde el centralismo, como el Plan de Desarrollo Urbano de 1970-1973, desarrollado por el Ministerio de Vivienda. En comparación con otros planes, es el único que propone la construcción de la Vía Expresa, la Vía de Evitamiento, la erradicación del Mercado de San Pedro, y la eliminación de la estación ferroviaria de San Pedro, con el fin de descongestionar el barrio de San Pedro, propuestas que hasta el día de hoy no se cumplen.

Por otro lado, las políticas institucionales que se han asumido desde el terremoto del año 1950, primero con la Misión Kubler, luego con la CRIF y, posteriormente, con el proyecto PER 39, básicamente establecen la defensa y conservación del patrimonio cultural inmueble prehispánico y los monumentos religiosos. Al final de estas gestiones, se restauraron la Casa del Almirante, la Casona de San Bernardo, la Casa Garcilaso, el Convento de Santo Domingo - Templo del Koricancha, la Almudena, el Seminario San Antonio Abad y el Paraninfo Universitario de la UNSAAC.

La creación del Plan Copesco, por la UNESCO en 1966, con el objetivo de mejorar la infraestructura turística en el eje Cusco-Puno-Desaguadero, ha significado en su primera etapa la mejora de la infraestructura turística. Se construyeron paradores turísticos; albergues juveniles, como el de Machu Picchu y Huayruropata; se asfaltó de la carretera Cusco-Sicuani; se restauraron monumentos prehispánicos e histórico-artísticos. Este último es un proyecto regional que ha perdido su objetivo principal, el cual consistía 
en mejorar la infraestructura turística. Con el tiempo, se ha convertido en una institución de manejo político por ser un proyecto especial del Gobierno regional.

La creación del INC en 1971 significó la conservación y protección del patrimonio cultural. Aparte de ver temas culturales, este organismo se dedica a restaurar monumentos prehispánicos y monumentos histórico-artísticos; por tanto, mejora sustantivamente la conservación del patrimonio.

En el año 1992, se aprobó, mediante una ordenanza municipal, el Código Municipal para la Protección de la Ciudad Histórica del Qosqo para la salvaguardia del patrimonio en dicha ciudad. Resulta ser un reglamento para la conservación y preservación de monumentos, pero no constituye un instrumento de gestión del Centro Histórico del Cusco. Se trata de un documento en el que, en la actualidad, en algunos casos no contemplados en el Plan Maestro del Centro Histórico, se aplica temas referentes a protección y conservación del patrimonio. Por ende, debe entenderse como un código conservacionista.

El Plan Maestro del Centro Histórico del Cusco es un instrumento de gestión importante, elaborado por un equipo técnico constituido por profesionales de la Municipalidad del Cusco. Es un documento importante que establece parámetros urbanísticos para el manejo del centro histórico, cuya vigencia rige hasta hoy y, además, es conservacionista y proteccionista.

\section{Análisis de la gestión municipal 2011 - 2014}

La gestión municipal del período 2011 - 2014, presidida por el Ec. Luis Flórez García, se ha caracterizado por desarrollar obras especialmente en la periferia de la ciudad, pero sin la decisión de ejecutar o planificar una verdadera gestión del centro histórico. Se limitó a ejecutar algunos proyectos de registro e inventario (ver Tabla 2), y obras denominadas Mejoramiento de la Transitabilidad Vehicular y Peatonal, consistentes en la pavimentación de calles, es decir, la construcción de calzadas y veredas con laja de piedra, y la construcción de postes de alumbrado público con diseños anacrónicos (ver Tabla 3).

\section{Análisis de los proyectos y planes para el Cusco y el Centro histórico, y las obras ejecutadas en el barrio de San Pedro en la gestión 2011-2014}

\section{El proyecto de mejoramiento de la gestión y manejo del Centro Histórico del Cusco}

Con un PIP N 74755 como denominación de gestión y manejo, al inicio del proyecto se presagiaba que se trataba de un proyecto de gestión, pero de acuerdo al proyecto se trataba del registro y catalogación de los ambientes urbanos e inmuebles del centro histórico que naturalmente incluía el barrio de San Pedro. Finalmente, resultó un trabajo importante que se realizó sin la participación de la Dirección Desconcentrada de Cultura, como causa de una falsa rivalidad de sus funcionarios con la Municipalidad (ver Figuras 15 y 16). Dicho proyecto se inició en 2011 y se concluyó en 2013.

\section{El proyecto de mejoramiento de la gestión del territorio urbano en el Centro histórico del Cusco}

El proyecto se inició en 2012 con PIP N 201774 . Se trató de un proyecto para actualizar el Plan Maestro del Centro Histórico del Cusco aprobado en 2005 y ejecutar los planes maestros de San Sebastián y San Jerónimo, con reglamentación actualizada para el Cusco. Como se puede apreciar, igual que todos los planes y códigos, es conservacionista y reglamentarista. Hasta hoy, no ha sido aprobado por el Concejo Municipal por falta de aprobación ciudadana y cuestiones políticas. 
devenir Vol. 6, N¹1, ENERO - JUNIO 2019, PP. 49-68 - ESTUDIOS I ISSN 2312-7562 I E-ISSN 2616-4949

UNIVERSIDAD NACIONAL DE INGENIERÍA, LIMA

doi: https://doi.org/10.21754/devenir.v6i11.633

Tabla 2. Registro e inventarios para el barrio de San Pedro - Cusco

\begin{tabular}{|c|c|c|c|c|}
\hline Año & Nombre & Entidad ejecutora & Contenido & Área \\
\hline $2011-2014$ & $\begin{array}{l}\text { Proyecto: } \\
\text { Mejoramiento de la } \\
\text { Gestión y Manejo del } \\
\text { Centro Histórico del } \\
\text { Cusco. }\end{array}$ & $\begin{array}{l}\text { Municipalidad } \\
\text { Provincial del } \\
\text { Cusco }\end{array}$ & $\begin{array}{l}\text { Registro y Catalogación de Inmuebles y Ambien- } \\
\text { tes Urbanos del Centro Histórico del Cusco, que } \\
\text { consiste en: } \\
\text {-Fichas de Catalogación de inmuebles y ambientes } \\
\text { urbanos. } \\
\text {-Relevamiento de inmuebles y ambientes Urbanos. }\end{array}$ & $\begin{array}{l}\text { Centro Histórico del } \\
\text { Cusco (incluye el } \\
\text { barrio de San Pedro) }\end{array}$ \\
\hline $2011-2014$ & $\begin{array}{c}\text { Proyecto: } \\
\text { Fortalecimiento e } \\
\text { Implementación del } \\
\text { Sistema Catastral } \\
\text { Urbano del Distrito del } \\
\text { Cusco. }\end{array}$ & $\begin{array}{l}\text { Municipalidad } \\
\text { Provincial del } \\
\text { Cusco. }\end{array}$ & $\begin{array}{l}\text { Inventario de inmuebles predio por predio, con: } \\
\text {-Área de terreno o lote } \\
\text {-Área construida } \\
\text {-Materiales de construcción } \\
\text {-Número de niveles o pisos } \\
\text {-Servicios básicos } \\
\text {-Ficha socioeconómica }\end{array}$ & $\begin{array}{l}\text { Distrito del Cusco } \\
\text { (incluye el Centro } \\
\text { Histórico del Cusco, } \\
\text { por tanto el barrio de } \\
\text { San Pedro). }\end{array}$ \\
\hline
\end{tabular}

Elaboración propia sobre la base de archivos de Liquidación de Obras y Proyectos, 2018.

Tabla 3. Proyectos de inversión pública realizadas en el barrio de San Pedro, Gestión 2011-2014

\begin{tabular}{|c|c|c|c|c|c|}
\hline Año & Nombre del proyecto & $\begin{array}{l}\text { Código } \\
\text { SNIP }\end{array}$ & Sector & Entidad ejecutora & $\begin{array}{l}\text { Monto } \\
\text { invertido }\end{array}$ \\
\hline \multirow{3}{*}{2011} & $\begin{array}{l}\text { Fortalecimiento e Implementación del Sistema Catastral Urbana } \\
\text { del Distrito del Cusco, Prov. Cusco }\end{array}$ & 75046 & $\begin{array}{l}\text { Desarrollo } \\
\text { Urbano }\end{array}$ & $\begin{array}{l}\text { Municipalidad Pro- } \\
\text { vincial del Cusco }\end{array}$ & $2^{\prime} 224,772.00$ \\
\hline & $\begin{array}{l}\text { Mejoramiento de la Gestión y Manejo del Centro Histórico del } \\
\text { Cusco - Cusco }\end{array}$ & 74755 & $\begin{array}{l}\text { Desarrollo } \\
\text { Urbano }\end{array}$ & $\begin{array}{l}\text { Municipalidad Pro- } \\
\text { vincial del Cusco }\end{array}$ & $1^{\prime} 716,603.00$ \\
\hline & $\begin{array}{l}\text { Mejoramiento de la Transitabilidad vehicular calle Qasccaparo } \\
\text { - Barrio San Pedro, Distrito de Cusco }\end{array}$ & 125985 & Transporte & $\begin{array}{l}\text { Municipalidad Pro- } \\
\text { vincial del Cusco }\end{array}$ & $2^{\prime} 325,556.00$ \\
\hline \multirow{7}{*}{2012} & $\begin{array}{l}\text { Mejoramiento de la Gestión y Manejo Centro Histórico del Cusco, } \\
\text { Distrito y Provincia del Cusco }\end{array}$ & 74755 & Gestión & $\begin{array}{l}\text { Municipalidad Pro- } \\
\text { vincial del Cusco }\end{array}$ & $1^{\prime} 716,603.00$ \\
\hline & $\begin{array}{l}\text { Mejoramiento de la Transitabilidad Vehicular y Peatonal, Calles Ave- } \\
\text { nida Alta y Avenida Baja (Barrio San Pedro) del Centro Histórico Cusco }\end{array}$ & 173270 & Transporte & $\begin{array}{l}\text { Municipalidad Pro- } \\
\text { vincial del Cusco }\end{array}$ & $2^{\prime} 591,282.00$ \\
\hline & $\begin{array}{l}\text { Mejoramiento de la Transitabilidad Vehicular y Peatonal, de la } \\
\text { calles Nueva Baja y Vitoque (Barrio San Pedro) - Cusco }\end{array}$ & 176463 & Transporte & $\begin{array}{l}\text { Municipalidad Pro- } \\
\text { vincial del Cusco }\end{array}$ & $1^{\prime} 912,555.00$ \\
\hline & $\begin{array}{l}\text { Mejoramiento del Sistema de Agua Potable y Desagüe de la Aveni- } \\
\text { da Arcopata y calle Meloc (Barrio San Pedro) - Cusco }\end{array}$ & 229348 & Saneamiento & $\begin{array}{l}\text { Municipalidad Pro- } \\
\text { vincial del Cusco }\end{array}$ & $435,742.33$ \\
\hline & $\begin{array}{l}\text { Mejoramiento del Servicio de Ordenamiento Territorial en la Pro- } \\
\text { vincia del Cusco - Cusco }\end{array}$ & 187512 & $\begin{array}{l}\text { Desarrollo } \\
\text { Urbano }\end{array}$ & $\begin{array}{l}\text { Municipalidad Pro- } \\
\text { vincial del Cusco }\end{array}$ & $6^{\prime} 320,226.00$ \\
\hline & $\begin{array}{l}\text { Mejoramiento de la Transitabilidad Vehicular y Peatonal en las } \\
\text { Calles Arcopata y Meloc (Barrio San Pedro) - Centro Histórico del } \\
\text { Cusco }\end{array}$ & 228888 & Transporte & $\begin{array}{l}\text { Municipalidad } \\
\text { Provincial del Cusco }\end{array}$ & $4^{\prime} 386,326.00$ \\
\hline & $\begin{array}{l}\text { Mejoramiento de la Gestión del Territorio Urbano en el } \\
\text { Centro Histórico del Cusco - Cusco }\end{array}$ & 201774 & $\begin{array}{l}\text { Desarrollo } \\
\text { Urbano }\end{array}$ & $\begin{array}{l}\text { Municipalidad Pro- } \\
\text { vincial del Cusco }\end{array}$ & $6^{\prime} 496,863.00$ \\
\hline \multirow{2}{*}{2014} & $\begin{array}{l}\text { Rehabilitación del Sistema de Saneamiento Básico en las Calles } \\
\text { Túpac Amaru, Trinitarias y Pasaje Gohering (Barrio San Pedro) - } \\
\text { Cusco }\end{array}$ & 230103 & Saneamiento & $\begin{array}{l}\text { Municipalidad Pro- } \\
\text { vincial del Cusco }\end{array}$ & $262,025.54$ \\
\hline & $\begin{array}{l}\text { Mejoramiento de la Transitabilidad Peatonal y Vehicular en las } \\
\text { Calles Nueva Alta y Apurímac (Barrio San Pedro) - Centro Histórico } \\
\text { del Cusco }\end{array}$ & 261867 & Transporte & $\begin{array}{l}\text { Municipalidad Pro- } \\
\text { vincial del Cusco }\end{array}$ & $3^{\prime} 973,430.00$ \\
\hline
\end{tabular}


Tradición y cambio en las Politicas urbanas y la Conservación del patrimonio en el Barkio de San Pedro del Centro Histórico de Cusco, DURANTE LA GESTIÓN MUNICIPAL 2011-2014

Pedro Fernández Diaz, Kenny Álvarez Tito, Victor Quispe Callo, Yoni Pacheco Huacac, María Vicente Pastor y Silvia Espinoza Lara doi: https://doi.org/10.21754/devenir.v6i11.633

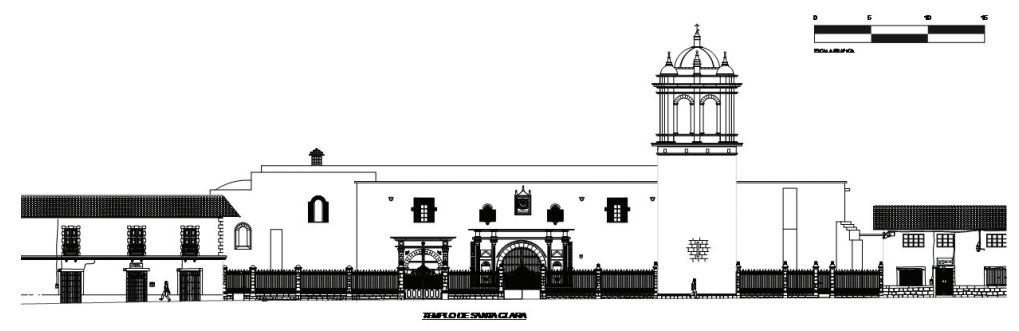

Figura 15. Registro y catalogación de ambientes urbanos. Templo De Santa Clara. Archivo de la Municipalidad Provincial del Cusco - Gerencia del Centro Histórico.

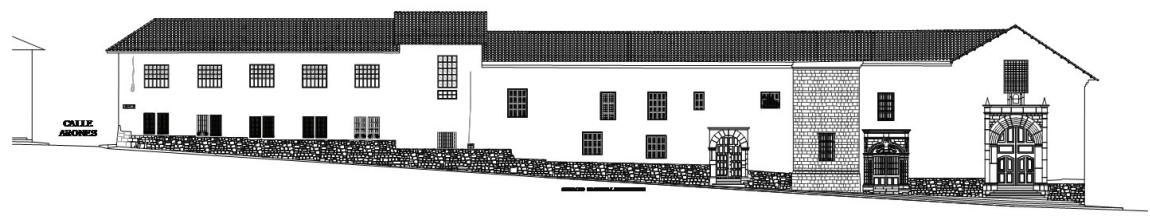

Figura 16. Registro y catalogación de inmuebles. Ambientes urbanos Colegio Nacional Educandas. Archivo de la Municipalidad Provincial del Cusco - Gerencia del Centro Histórico.

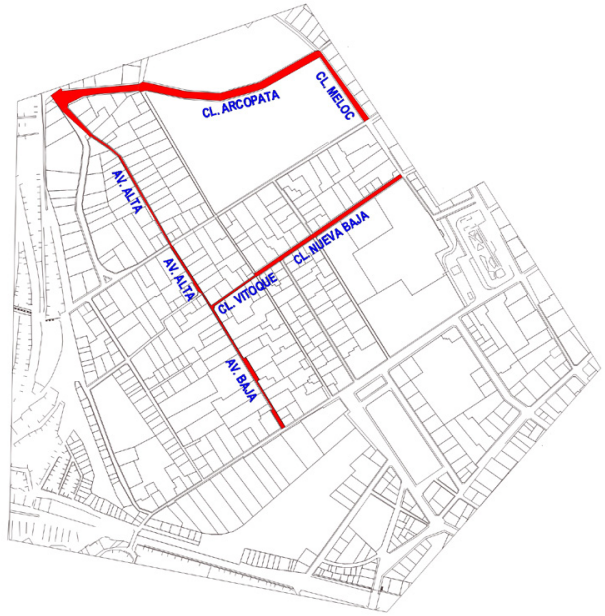

Figura 17. Mejoramiento de la transitabilidad vehicular y peatonal, barrio San Pedro, calles Arcopata, Meloc, Nueva Baja, Vitoque, Avenida Baja y Avenida Alta. Gestión 2011-2014. Elaboración propia.

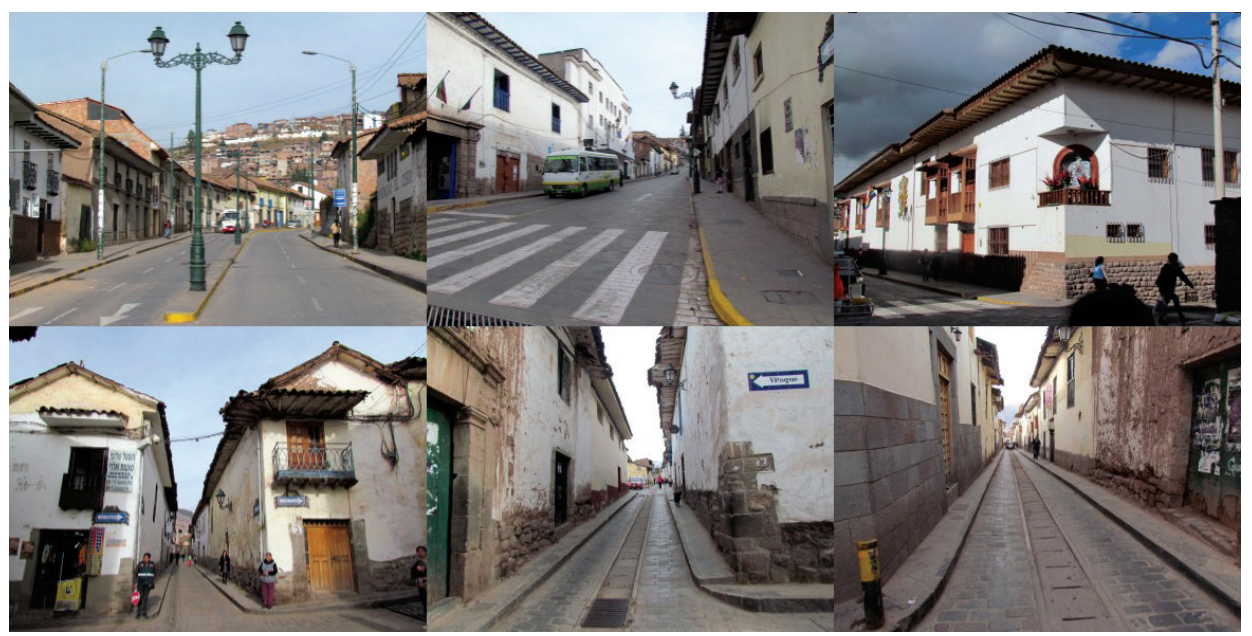

Figura 18. Mejoramiento de la Transitabilidad Vehicular y Peatonal, calles Arcopata y Meloc, Nueva Baja y Vitoque, Avenida Alta y Avenida Baja (postes de alumbrado con diseño anacrónico). Archivo personal del autor. 
devenir Vol. 6, N¹1, ENERO - JUNIO 2019, PP. 49-68 - ESTUDIOS I ISSN 2312-7562 | E-ISSN 2616-4949

UNIVERSIDAD NACIONAL DE INGENIERÍA, LIMA

doi: https://doi.org/10.21754/devenir.v6i11.633

\section{El Proyecto de Mejoramiento del Servicio de Ordenamiento Territorial en la Provincia del Cusco}

Este proyecto se inició en el año 2013 con PIP N 187512. Se trató de un proyecto que ha ejecutado siete planes: Plan de Desarrollo Urbano (PDU), Plan Urbano Distrital (PUD), Plan de Desarrollo Metropolitano (PDM), Plan de Ordenamiento Territorial (POT), Plan Específico - parque Industrial (PE), Plan Integral - Molleray (PI) y Esquema de Ordenamiento Urbano - Cusibamba (EO). Todos estos planes, en su mayoría, han sido aprobados, como el PDM, PDU, PUD y OT, que consideran al Centro Histórico del Cusco como una zona de tratamiento especial.

\section{Obras con el nombre Mejoramiento de la Transitabilidad Vehicular y Peatonal}

Se han ejecutado obras en el barrio de San Pedro: calles Avenida Alta y Avenida Baja, Nueva Baja y Vitoque, avenida Arcopata y calle Meloc (ver Figura 17 y Figura 18).

\section{Problemática del barrio de San Pedro}

Aparte de la problemática del Centro Histórico del Cusco en general, que se explica a partir de la falta de una continuidad, cambio y revitalización urbana en manzanas deterioradas, en el barrio de San Pedro se han determinado tres problemas principales: congestionamiento vehicular y peatonal en la Plaza de San Pedro por la existencia del Mercado Central y la estación ferroviaria; la existencia de comercio ambulatorio en los alrededores del Mercado Central, pues los comerciantes de ventas de frutas y comestibles han invadido las calles aledañas; $y$, por último, la existencia de casonas abandonadas sin techo por decisión de sus propietarios, que no tienen capacidad económica para asumir el costo de una restauración y conservación tal como lo exige el Ministerio de Cultura y la Municipalidad y, por ello, deciden abandonarlas hasta venderlas al mejor postor, que generalmente es un extranjero que desea construir un hotel (ver Figuras 19 y 20).

\section{Instituciones a cargo de la gestión del centro histórico del Cusco}

Para la gestión y manejo del Centro Histórico del Cusco, en cuyo interior se encuentra el barrio de San Pedro, no existe una propuesta de quién es el ente gestor. El Ministerio de Cultura y la Municipalidad Provincial del Cusco no coordinan las acciones a adoptar. Existe falta de coordinación entre ambas instituciones, a raíz de que se plantea una serie de razonamientos para crear una unidad de gestión.

La Ley 28296, Ley del Patrimonio Cultural de la Nación, otorga competencias al Ministerio de Cultura, en lo que se refiere a conservación y protección del patrimonio cultural material e inmaterial, es decir, solamente en lo cultural.

La Ley Orgánica de Municipalidades N 27972 otorga competencias para el manejo integral de las ciudades a las municipalidades. De acuerdo a esta ley, es la única institución que otorga licencias de obra.

La Ley 29090 establece que se conformen comisiones técnicas de centros históricos, donde el Ministerio de Cultura participe con sus delegados ad hoc, dos arquitectos y un arqueólogo para la calificación de proyectos presentados ante la Municipalidad en el Centro Histórico.

En diferentes foros y eventos, se ha planteado la posibilidad de conformar una Unidad de Gestión del Centro Histórico del Cusco, conformada por el Ministerio de Cultura y la Municipalidad Provincial del Cusco para la gestión y manejo del Centro Histórico del Cusco, propuesta que no ha sido formalizada. 


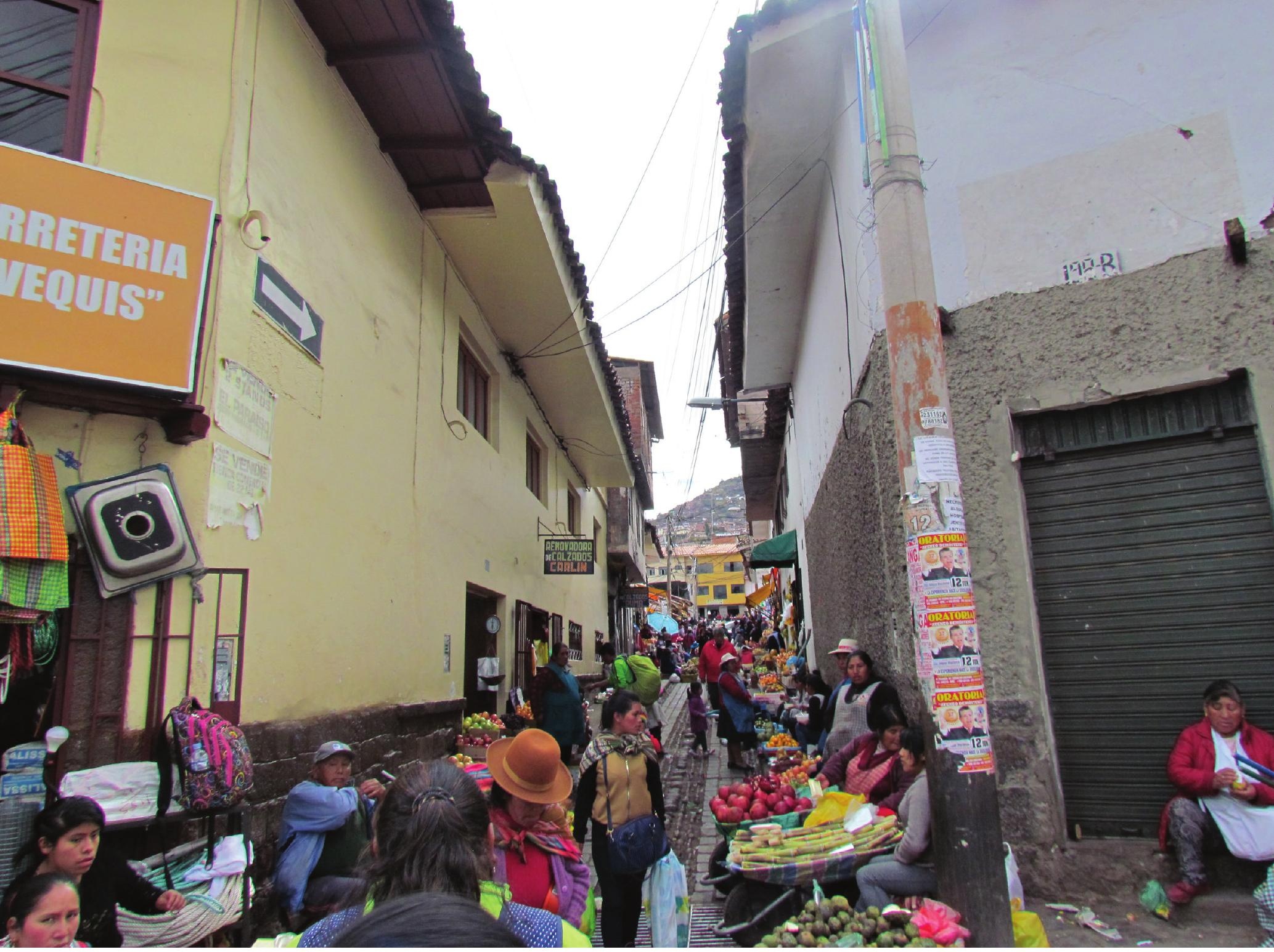

El instrumento de gestión actual para el manejo del centro histórico es el Plan Maestro del Centro Histórico del Cusco, aprobado en 2005, elaborado por equipos de profesionales del Ministerio de Cultura y la Municipalidad Provincial.

Finalmente, es la Municipalidad Provincial la que debe liderar la gestión y el manejo del centro histórico por ser el organismo competente y multisectorial. El Ministerio de Cultura, por su carácter sectorial, participa en lo referente a patrimonio cultural material e inmaterial.

\section{Conclusiones}

El barrio de San Pedro del Centro Histórico del Cusco debe mantenerse vivo, porque la historia es dinámica y no estática; por tanto, debe mostrar la continuidad y cambio de todas sus épocas, inclusive la actual.

Es necesario crear un ente gestor, constituido dentro de la Municipalidad Provincial del Cusco, conformada por entidades públicas y privadas que lideren el proceso de gestión y manejo del Centro Histórico, con respaldo político y aprobación del Concejo Municipal, de manera que tengan la capacidad de conciliar relaciones sociales e involucren a la sociedad civil, elaborando proyectos que nazcan de la voluntad ciudadana y gestionando financiamiento ante entidades internacionales como el Banco Interamericano de Desarrollo.

Figura 19. Comercio ambulatorio en calles aledañas al Mercado Central. Archivo personal del autor.

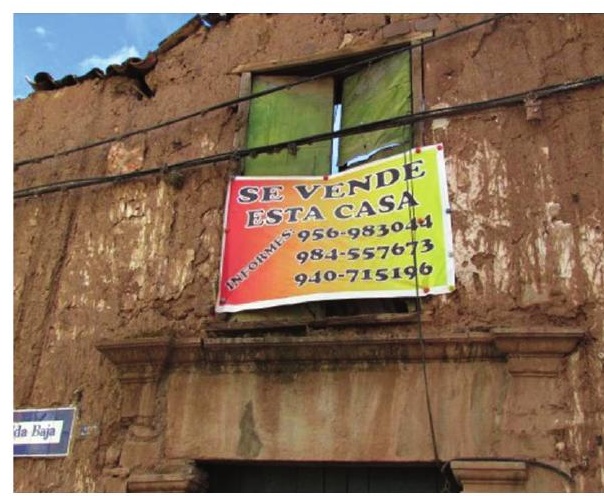

Figura 20. Casona abandonada, con aviso de venta, en la calle Avenida Baja. Archivo personal del autor. 
devenir Vol. 6, N¹1, ENERO - JUNIO 2019, PP. 49-68 - ESTUDIOS I ISSN 2312-7562 | E-ISSN 2616-4949

UnIVERSIDAD NACIONAL DE INGENIERÍA, LIMA

doi: https:// doi.org/10.21754/devenir.v6i11.633

El término palimpsesto, que emplea el Arq. Fernando Carrión, debe ser aplicado en la gestión y manejo del barrio de San Pedro y el Centro Histórico del Cusco en general y, con ello, en su evolución, muestre huellas del pasado.

Es necesario erradicar el comercio ambulatorio en el barrio de San Pedro, existente en los alrededores del mercado del mismo nombre, por ser un factor de deterioro del centro histórico.

Es importante fortalecer a las instituciones públicas que manejan el centro histórico y evitar que se deteriore. Como manifiesta el Arq. Hayakawa (2015), los centros históricos se deterioran cuando también sus instituciones están deterioradas.

El ente gestor debe, como prioridad, resolver el problema de congestión vehicular con un análisis y estudio de esta problemática, incentivando la construcción de la Vía Expresa y la Vía de Evitamiento que en el plan de 1973 se había propuesto para descongestionar el centro histórico.

\section{Referencias}

Agurto Calvo, S. (2001). La traza urbana de la ciudad inka. Lima, Perú: Nerea.

Belaunde, P. (1990). Centros históricos América Latina. Colombia: Ed. Colección Somo Sur. Escala - Colombia 1990.

Ferreira A, R., \& Ladrón de Guevara, O. (1989). Situación del patrimonio monumental. Crónicas urbanas. Recuperado de https:/ /ferropedia.es/wiki/perurail

Halanocca, R. N. (2011). Estado y cultura. Recuperado de www./INC.estadoycultura.2009.htm. Obtenido de cybertesis.uni.edu.pe/bitstream/uni/224/1/navarro_hr.pdF

Kubler G. (1951). Rescontrucción de la ciudad del Cusco. Cusco, Perú.

Municipalidad del Cusco. (1993). Código municipal para la proteccion de la ciudad de Qosqo. Cusco, Perú.

Municipalidad del Cusco. (2013). Registro de catalogación de ambientes e inmuebles urbanos. Cusco, Perù.

Municipalidad del Cusco \& Instituto Nacional de Cultura. (2005). Plan maestro del Centro Histórico del Cusco. Cusco, Perú.

Sanchez P. (1994). Tradición y modernidad en la tecnología. Lima, Perú: Epigrafe.

Villegas A, E. (1990). Centro histórico del Cusco. Rehabilitación urbana y vivienda. Lima, Perú: Universitaria. 